\title{
ANÁLISIS TAXONÓMICO MOLECULAR DE INDIVIDUOS DEL GÉNERO LATHYRUS HALLADOS EN EL EXTREMO NORTE DE ChILE, Mediante DNA BARCoding
}

\author{
MOLECULAR TAXONOMIC ANALYSIS OF INDIVIDUALS OF THE GENUS LATHYRUS \\ FOUND IN THE NORTHERN EXTREME OF CHILE, USING DNA BARCODING
}

\author{
Mariana Arias Aburto ${ }^{1}$, Delia Ramírez Medina ${ }^{1}$ y Roberto Contreras Díaz ${ }^{1,2 *}$ (D)
}

1. Centro Regional de Investigación y Desarrollo Sustentable de Atacama (CRIDESAT), Universidad de Atacama, Copayapu 485, Copiapó, Chile.

2. Departamento de Educación, Facultad de Humanidades y Educación, Universidad de Atacama, Copayapu 485, Copiapó, Chile.

*roberto.contreras@uda.cl

Citar este artículo ARIAS ABURTO, M., D. RAMÍREZ MEDINA y R. CONTRERAS DÍAZ. 2020. Análisis taxonómico molecular de individuos del género Lathyrus hallados en el extremo norte de Chile, mediante DNA barcoding. Bol. Soc. Argent. Bot. 55: 479-492.

DOI: https://doi. org/10.31055/1851.2372.v55. n3.28030

Recibido: 28 Marzo 2020

Aceptado: 1 Septiembre 2020 Publicado: 30 Septiembre 2020 Editora: Viviana Solís Neffa (iD

ISSN versión impresa 0373-580X ISSN versión on-line 1851-2372

\section{SUMMARY}

Background and aims: The present investigation corresponds to a molecular taxonomic analysis of floral samples of plants naturally established in a remote area of the Atacama Desert, Arica-Parinacota Region, Chile. In the first instance, the samples were morphologically attributed to the genus Lathyrus, however, according to current literature, no individuals of this genus have been registered in the region, given this, confusion has been generated in the identification of the collected samples. Therefore, the present research aims to genetically identify the presumably Lathyrus species, using DNA Barcoding.

M\&M: In the present study we evaluated these individuals by a phylogenetic analysis to determine their taxonomic identity from ITS (nuclear) sequence and $p s b A$, matK and rpoC1 (plastidic) sequences.

Results: The results demonstrated that the individuals are related to the species Lathyrus odoratus.

Conclusions: The four DNA barcoding loci allowed the samples to be genetically identified as $L$. odoratus, which is found growing naturally in Chile.

\section{KEY WORDS}

DNA barcoding, ITS, Lathyrus odoratus, matK, psbA-trnH, rpoC1.

\section{RESUMEN}

Introducción y objetivos: La presente investigación corresponde a un análisis taxonómico molecular de muestras florales obtenidas de plantas establecidas naturalmente en una zona recóndita del Desierto de Atacama, Región de AricaParinacota, Chile. En primera instancia, las muestras morfológicamente se atribuyeron al género Lathyrus, sin embargo, conforme a la literatura actual, no se han registrado individuos de este género en la región, dado esto, se ha generado confusión en la identificación de las muestras colectadas. Por lo cual, la presente investigación tiene por objetivo identificar genéticamente las especies presuntamente de Lathyrus, mediante DNA Barcoding.

M\&M: En el presente estudio se evaluaron estos individuos mediante un análisis filogenético para determinar su identidad taxonómica a partir de secuencias ITS (nuclear) y secuencias $p s b A$, matK y rpoC1 (plastídicas).

Resultados: Los resultados demostraron que los individuos están relacionados a la especie Lathyrus odoratus.

Conclusiones: Los cuatro loci de DNA barcoding, permitieron identificar genéticamente las muestras como $L$. odoratus, el cual se encuentra creciendo de manera natural en Chile.

Palabras clave

DNA barcoding, ITS, Lathyrus odoratus, matK, psbA-trnH, rpoC1.

\section{INTRODUCCIÓN}

El desierto de Atacama se encuentra en la región Norte Grande de Chile y es considerado el desierto más antiguo y continuamente más seco de la Tierra, siendo árido desde el período Jurásico e hiperárido desde el Mioceno (Hartley et al., 2005). La mayoría de los grupos 
de plantas que se encuentran en el desierto de Atacama están representados por pocas especies, y solo unos pocos géneros son diversos (Heibl \& Renner, 2012). La Región de Arica-Parinacota se encuentra dentro del Norte Grande de Chile, $\mathrm{y}$ posee una gran diversidad de flora vascular concentrada en mayor grado en la provincia de Parinacota (Luebert \& Gajardo, 2005; Faúndez et al., 2014). De acuerdo a Gatica-Castro et al. (2015), la flora de la Región de Arica-Parinacota está integrada por 596 especies, de ellas 98 son endémicas de Chile y 10 son endémicas de la región. En un recorrido realizado por esta región, específicamente en la Quebrada de Vitor, descubrimos algunos individuos de plantas florales (de color púrpura y crema) que de acuerdo a sus características morfológicas podrían pertenecer al género Lathyrus L. Sin embargo, hacia el norte de Chile, desde la Región de Arica-Parinacota hasta la Región de Tarapacá no se han registrado especies de este género (Rodriguez et al., 2018).

El género Lathyrus es miembro de la tribu Vicieae (Familia Fabaceae) que comprende aproximadamente 160 especies (Simola, 1968; Kupicha, 1983; Skiba et al., 2007). Principalmente se encuentran distribuidas en los climas templados del hemisferio norte, siendo el principal centro de diversidad del género la región Mediterránea Oriental; mientras que el oeste de los Estados Unidos y la región sur de Argentina y Chile, representan centros de diversidad secundarios (Burkart, 1935, 1942; Senn, 1938; Kenicer, 2008). Todas las especies de Lathyrus son herbáceas, con alrededor de 40 especies anuales y 120 perennes (Kenicer, 2008).

Desde un punto de vista morfológico, el género Lathyrus se caracteriza por presentar tallos angulosos, hojas pinnadas con un zarcillo terminal, flores solitarias que varían en color de azul, rojo y blanco, así como vainas que contienen de tres a cinco semillas (Skiba et al., 2007). Todas las especies de Lathyrus de Sudamérica poseen hojas con un par de foliolos, excepto $L$. macropus Gill y L. multiceps Clos, en cambio las especies de Lathyrus de Norteamérica poseen hojas con dos o más pares de foliolos, excepto $L$. pusillus Ell. (Burkart, 1942). Los datos de ADN sugieren que las especies sudamericanas están más estrechamente relacionadas con las especies del oeste de Eurasia (Kenicer, 2008). La mayoría de las especies del género Lathyrus son diploides $(2 \mathrm{n}=14)$ (Naravan \& Durrant 1983; Yamamoto et al., 1984; Chalup \& Seijo, 2007).

En Chile, se ha registrado el género Lathyrus creciendo de manera natural desde la Región de Antofagasta hasta la Región de Magallanes, habiendo específicamente tres especies endémicas: $L$. berteroanus Colla ex Savi, $L$. lomanus I.M. Johnst., L. subandinus Phil.; trece especies nativas: L. cabrerianus Burkart, $L$. campestris Phil., L. crassipes Gillies ex Hook. \& Arn., L. hookeri G. Don, L. macropus Gillies ex Hook. \& Arn., L. magellanicus Lam. var. glaucescens Speg., L. magellanicus Lam. var. longipes (Phil.) Burkart, L. magellanicus Lam. var. magellanicus, L. magellanicus Lam. var. tucumanensis Burkart, L. multiceps Clos, L. nervosus Lam., L. pubescens Hook. \& Arn., L. pusillus Elliott; y cuatro especies exóticas asilvestradas y naturalizadas: $L$. cicera L., $L$. japonicus Willd., L. sativus L. y L. hirsutus L. (Burkart, 1942; Calvo \& Moreira-Muñoz, 2018; PNUD, 2017; Rodriguez et al., 2018). Adicionalmente, se han ingresado semillas de $L$. odoratus L. a Chile, como parte de solicitud de importación comercial para su venta con fines ornamentales (SAG, 2020).

La diferenciación de las especies del género Lathyrus es dificultosa debido a su homoplasia morfológica, como la forma de la estípula, el número de foliolos y la presencia de zarcillos, siendo dicha homoplasia el principal desafío en su clasificación (Kupicha, 1983; Kenicer et $a l ., 2005)$. Esta preponderancia de caracteres compartidos ha llevado a la realización de estudios filogenéticos moleculares en Lathyrus, en los cuales se ha dividido a este género en 12 o 13 secciones (Czefranova, 1971; Kupicha, 1983; Asmussen \& Liston, 1998; Kenicer et al., 2005).

El "DNA Barcoding" (código de barras de $\mathrm{ADN}$ ) es una técnica de diagnóstico para la identificación de especies, que utiliza una región de ADN corta y estandarizada (Lahaye et al., 2008; Contreras et al., 2020a). El código de barras del ADN en plantas implica la secuenciación de segmentos cortos del genoma de cloroplastos o nuclear para comparar los resultados con secuencias de referencia ortólogas disponibles en bases de datos públicas como BOLD (www. 


\section{Arias Aburto et al. - Análisis taxonómico molecular en Lathyrus}

boldsystem.org) y GenBank (www.ncbi.nlm. nih.gov/genbank) (Barcaccia et al., 2016). Para la identificación de plantas, no ha habido consenso respecto del uso de una sola secuencia estandarizada, sin embargo, el Consorcio para el Código de Barras de la Vida CBOL (CBOL, 2009), ha propuesto varias combinaciones de loci de ADN plastidial, cuatro genes codificadores (matK, rbcL, rpoB y rpoCl) y espaciadores no codificantes $(a t p F-a t p H, t r n H-p s b A, y$ psbK$p s b I$ ), siendo $r b c L$ y matK, propuestos como un "código de barras central" para plantas (Hollingsworth et al., 2011; Contreras et al., 2020b). La región nuclear "internal transcribed spacer(ITS)" ha sido utilizada de manera eficiente para la clasificación seccional a nivel del género Lathyrus y para reconstruir filogenias (Kenicer et al., 2005). Así también, regiones rpoC (rpoCl, intrón, rpoC2 y espaciador intergénico) e $I R 2$ ( $p s b A, t r n H-G U G$, parte de $n d h F$ y espaciadores intergénicos) fueron analizadas en 42 especies de Lathyrus, confirmando la clasificación de 6 a 8 secciones (Asmussen \& Liston, 1998), mientras que el gen mat $K$ se ha utilizado para la filogenia de especies de Lathyrus de Irán y de otras regiones de Asia (Oskoueiyan et al., 2014). Estos marcadores han logrado ser eficaces en la discriminación de especies de Lathyrus, por lo tanto, utilizaremos datos de secuencias de ITS, rpoC1, psbA-trnH y matK para clasificar algunos individuos colectados en la Región de Arica-Parinacota. La presente investigación tiene por objetivo identificar genéticamente individuos presuntamente de Lathyrus hallados en la Quebrada Vitor de la Región de AricaParinacota, mediante DNA Barcoding, con el fin de identificar especies no registradas a nivel regional y, además, explorar un método eficiente para un género donde la homoplasia de los caracteres morfológicos es alta.

\section{Materiales y Métodos}

\section{Material vegetal}

Se colectaron muestras de plantas en la Quebrada de Vitor (también llamada Quebrada de Chaca, donde fluye de manera intermitente el río Codpa), ubicada en la Región de Arica y Parinacota, Chile, denominadas Lathyrus 829 (flor color

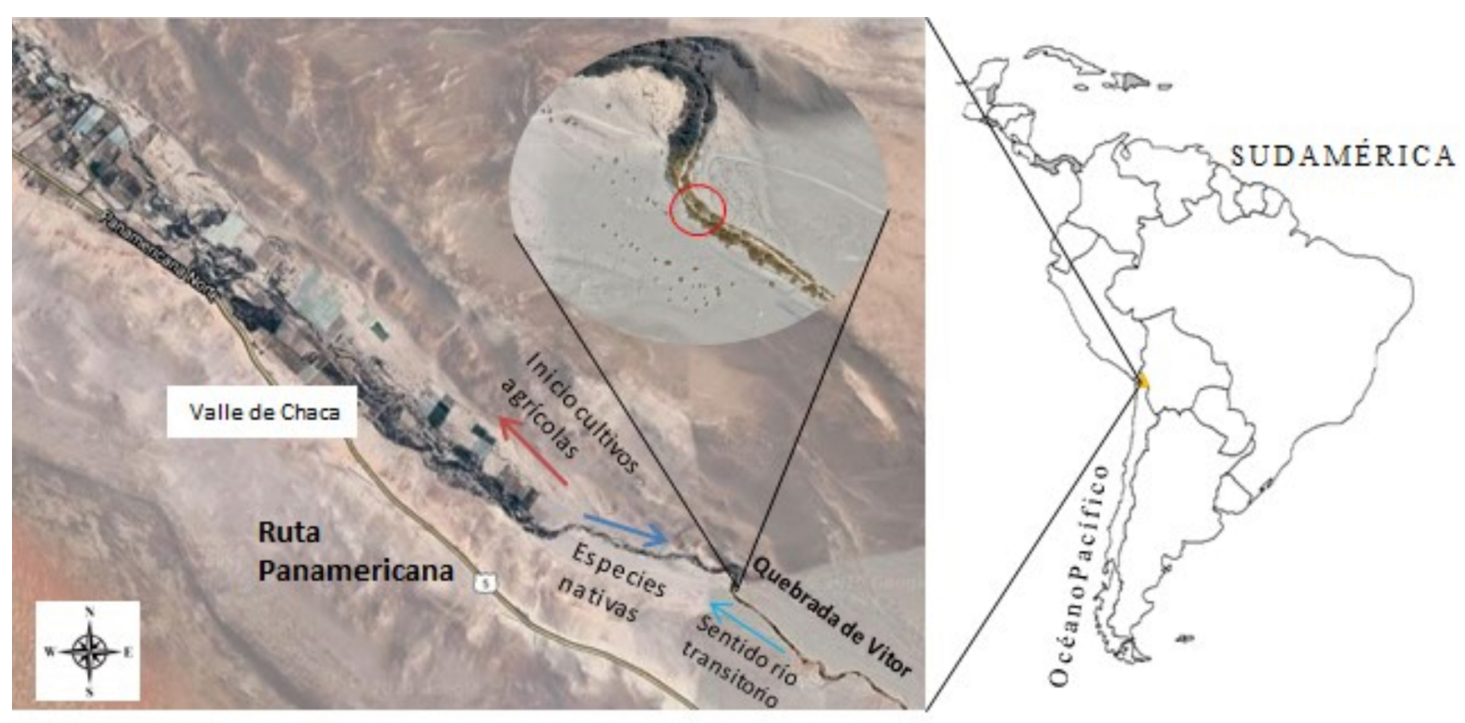

Fig. 1. Localización geográfica donde se colectaron las muestras Lathyrus 829 y 830 . La flecha de color rojo indica la dirección y el sentido donde comienzan los cultivos agrícolas en la Quebrada de Vitor y la flecha de color azul indica la dirección y el sentido donde se posicionan las especies nativas en la misma quebrada (sin intervención humana). El círculo rojo señala la localización exacta donde fueron colectadas las muestras. 
crema/fucsia) (18 50'23,22"S 70 6'34,53”W, altitud $422 \mathrm{msnm}$ ) y Lathyrus 830 (flor color púrpura) (18 50’23,37'S $70^{\circ} 6{ }^{\prime} 34,64^{\prime \prime} \mathrm{W}$, altitud $422 \mathrm{msnm}$ ) (Fig. 1). En la Figura 1 se pueden observar la ubicación de los cultivos agrícolas y las especies nativas presentes en la Quebrada de Vitor. Las muestras colectadas se observaron creciendo naturalmente en la Quebrada de Vitor, asociada a las especies Anadenanthera colubrina (Vell.) Brenan, Phragmites australis (Cav.) Trin. ex Steud., Atriplex sp. y Tessaria absinthioides (Hook. \& Arn.) DC., entre otras (Fig. 2). Se hizo una revisión descriptiva de las muestras (Lathyrus 829 y 830) de acuerdo a las claves definidas por Luchetti (2008). Las muestras fueron depositadas en el Herbario del Departamento de Silvicultura y Conservación de la Naturaleza de la Universidad de Chile (EIF, Index Herbariorum Code), con el código EIF13778 (Lathyrus 829) y EIF13779 (Lathyrus 830).
Extracción de ADN y secuenciación de marcadores barcode

La extracción de ADN se realizó con el método CTAB/fenol-cloroformo-alcohol isoamílico/ columna de sílice, descrito por Contreras et al. (2019). La amplificación del marcador nuclear ITS y marcadores plastídicos $r p o C 1, p s b A \mathrm{y}$ matK se realizaron en una reacción de PCR con las siguientes parejas de cebadores: rpoC1 (1F 5'-GTGGATACACTTCTTGATAATGG-3'; 4R 5'-CCATAAGCATATCTTGAGTTGG-3') (Kress et al., 2005); ITS1-ITS2 (P674 5'-CCTTATCATTTAGAGGAAGGAG-3'; ITS-4 5'-TCCTCCGCTTATTGATATGC-3') (Stanford et al., 2000; Kress et al., 2005); matK (2.1f 5'-CCTATCCATCTGGAAATCTTAG-3'; 1326R 5 '- TCTAGCACACGAAAGTCGAAGT-3') (Cuénoud et al., 2002; Dong et al., 2013); y psbA-trnH (trnHf05 5'-GTTATGCATGAACGTAATGCTC-3'; $p s b A 3 f$
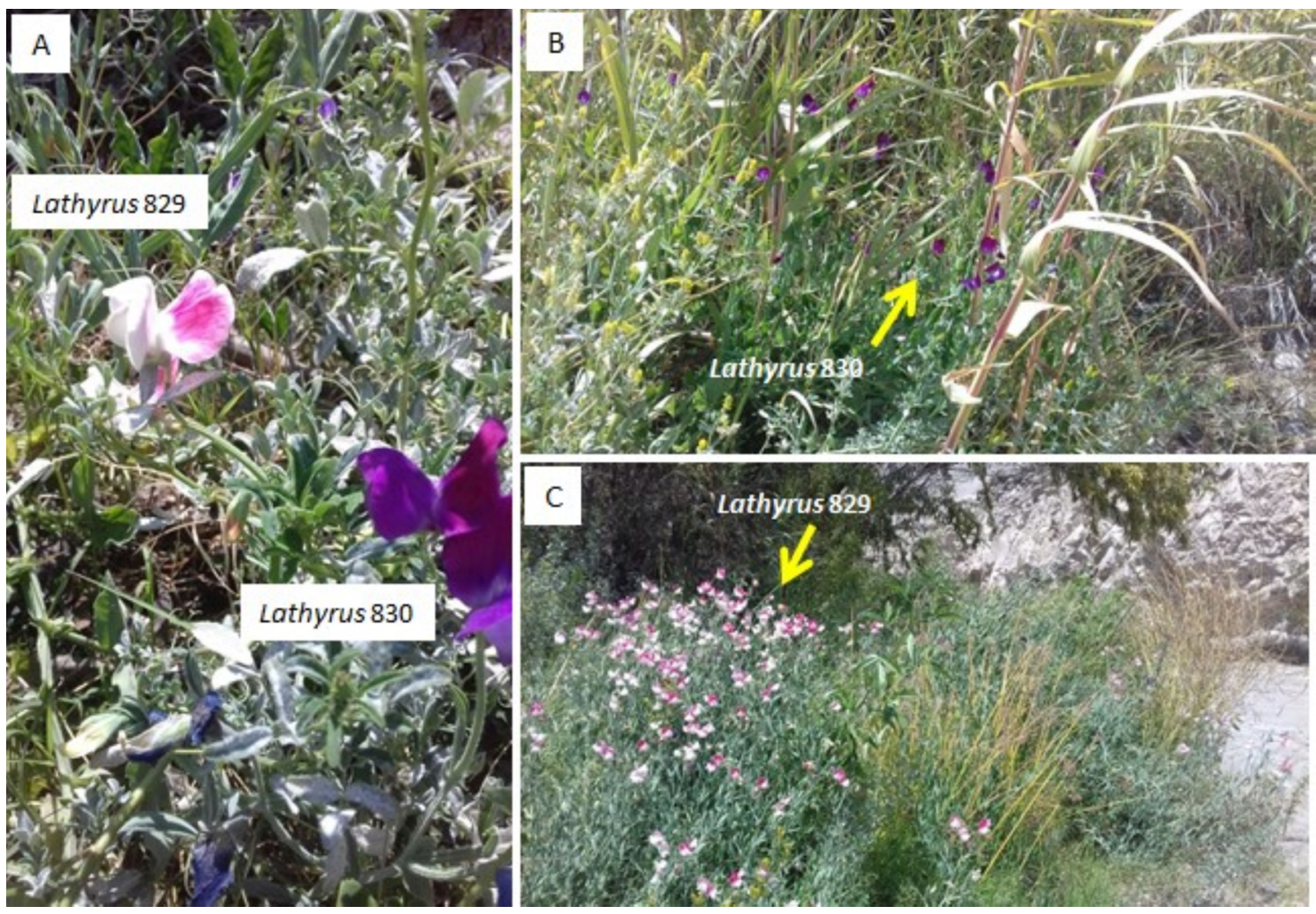

Fig. 2. A: Flor de Lathyrus 829 color blanco-fucsia y flor de Lathyrus 830 de color púrpura. B: Lathyrus 830 ; C: Lathyrus 829. 


\section{Arias Aburto et al. - Análisis taxonómico molecular en Lathyrus}

5'-CGCGCATGGTGGATTCACAATCC-3') (CBOL, 2009). Las reacciones de PCR con cada pareja de cebador se preparó a un volumen total de $24 \mu \mathrm{L}$ como se describe a continuación: 12 $\mu \mathrm{L}$ de Master Mix SapphireAmp Fast PCR 2X (Takara-Clontech, Kusatsu, Japón), 1,5 $\mu \mathrm{L}$ de cada cebador forward y reverse $(5 \mu \mathrm{M}), 3 \mu \mathrm{L}$ de agua libre de nucleasas y $6 \mu \mathrm{L}$ de $\mathrm{ADN}$ genómico (5 ng $\mu \mathrm{L}^{-1}$ ). Las amplificaciones se realizaron en un termociclador MultiGene OptiMax (Labnet International, Edison, USA) con las siguientes condiciones: un paso inicial de $10 \mathrm{~min}$ a 95 ${ }^{\circ} \mathrm{C}, 35$ ciclos de amplificación con $40 \mathrm{~s}$ a 95 ${ }^{\circ} \mathrm{C}, 40 \mathrm{~s}$ de temperatura de anillamiento según marcador (matK $55^{\circ} \mathrm{C}$, ITS $56^{\circ} \mathrm{C}$, rpoCl $53^{\circ} \mathrm{C}$ y psbA-trn $H 58^{\circ} \mathrm{C}$ ) y $40 \mathrm{~s}$ a $72{ }^{\circ} \mathrm{C}$, seguido por un paso de extensión final de $7 \mathrm{~min}$ a $72{ }^{\circ} \mathrm{C}$. Los productos de PCR fueron visualizados en geles de agarosa a $1,5 \%$, en tampón TBE $0,5 \mathrm{X}$ y teñido con GelRed ${ }^{\mathrm{TM}}$ Nucleic Acid Gel Stain a 0,1\% (Biotium, California, USA). Luego se purificó el producto de PCR con el kit de purificación Kit Wizard SV Gel and PCR Clean-Up System (Promega, Wisconsin, USA) y finalmente se envió a secuenciar a la empresa Macrogen Inc. (Corea del Sur).

\section{Análisis de datos}

Se editaron las secuencias de ADN "Forward" y "Reverse" con el software Chromas Pro v1 (Technelysium Pty, Ltd) y se ensamblaron utilizando el programa DNA Baser Sequence Assembler (v4.10) donde se aplicaron ajustes y análisis automáticos predeterminados para la edición de "contig" (Biosoft, 2012). Para realizar los análisis se descargaron varias secuencias de especies del género Lathyrus que mostraron máximo puntaje de alineación con nuestro segmento consultado en "GenBank" (BLASTn), siendo en total 10 secuencias para el marcador ITS (JN115031, MN736435, DQ311968, AY839344, DQ311967, AY839383, AY839359, AY839405, AM401152, JQ309787), 13 secuencias rpoC1 (KJ850238，KJ850235, KJ806193, KJ806196, KJ806195，KJ806199，KJ850236，KJ806202, KP126867, KJ806192, KJ806200, KJ806201, KJ850237), 7 secuencias psbA-trnH (KJ850237, JX505926, HE966680, JX505951, JX505952, KJ806192，KJ806193), 9 secuencias matK (KJ850237，JX505798，JX505815，AF522085,
KX676551，KM487289，KJ806201，KJ850238, KJ850236) y otras secuencias de Lathyrus (KJ806236, KJ806198) (Tabla S1). Para cada marcador se usaron dos secuencias de ADN del género Vicia L., como grupo externo, siendo estas Vicia cracca L. (JQ309787, JX505993), Vicia sativa var angustifolia (L.) ex Reichard (KJ787206), Vicia pisiformis L. (JX506029), Vicia nigricans Hook. \& Arn. (AF522155), Vicia crocea (Desf.) B. Fedtsch (HM026406), Vicia sepium L. (MG682352) y Vicia ramuliflora L (MN758738). Las secuencias de las muestras y las secuencias descargadas se alinearon usando el software MEGA 6 (Tamura et al., 2013), para cada uno de los marcadores "barcode" usados.

Para evaluar la filogenia se utilizó el método de agrupamiento Neighbor Joining (NJ) e Inferencia Bayesiana (IB). El análisis NJ y las distancias genéticas por pares de especies fueron inferidos basados en el modelo Tamura-Nei (Tamura \& Nei, 1993) utilizando el software MEGA6 (Tamura et al., 2013) y para la confiabilidad del soporte de los análisis se utilizaron 1000 réplicas de bootstrap (BS). El análisis de IB se llevó a cabo con MrBayes 3.2 (Ronquist et al., 2012). Se utilizó el programa Mr.Modeltest 2.3 (Nylander, 2008) para explorar el mejor modelo de evolución que se ajusta a los datos de las secuencias de ADN, basado en "corrected Akaike Information Criterion (AICc)". Una prueba de razón de probabilidad jerárquica implementada con el programa MrModeltest y AICc sugirió que el modelo de evolución que mejor se ajusta es $\mathrm{SYM}+\mathrm{G}$ para datos ITS, GTR $+\mathrm{G}$ para datos matK, GTR+I para datos psbA-trnH, GTR+I+G para datos rpoCl y para datos concatenados de marcadores de cloroplasto ( $m a t K+p s b A+r p o C 1)$. Se efectuaron dos análisis independientes de Cadenas de Monte Carlo Markov (CMCM) que consta cada una de 3.000 .000 generaciones, obtenidos con una desviación promedio de frecuencias inferior a 0,006. Los árboles se muestrearon con una frecuencia cada 1000 generaciones, y el $25 \%$ de los primeros árboles se desecharon como "burn-in". Se utilizó el programa TRACER v. 1.5 (Rambaut \& Drummond, 2007) para verificar la estabilidad de la probabilidad general y la convergencia entre generaciones de los análisis ejecutados con $\mathrm{Mr}$ Bayes. La fiabilidad de los clados en el análisis 
bayesiano se evaluó por medio de la probabilidad a posteriori (PP). Los valores de PP bajo 0,80 se consideraron de bajo soporte; entre 0,80 y 0,89 se consideraron como moderado; y los valores de PP superiores a 0,90 como alto soporte. En el análisis, los valores de bootstrap (BS) para los nodos internos se estimaron con 100 réplicas, siendo confiables los valores mayores a 70 . Se considera generalmente que un grupo está apoyado de forma concluyente cuando el valor de "bootstrap" es mayor a 70, lo que generalmente corresponden a una probabilidad del $95 \%$ de consistencia del agrupamiento (Hillis \& Bull, 1993). Todos los dendrogramas fueron editados usando el programa FigTree 1.4.0 (Rambaut, 2012).

\section{Resultados}

El árbol filogenético de las secuencias ITS, mediante el método NJ, presenta una separación basal de dos grupos monofiléticos y dos especies de Vicia ( $V$. cracca y V. sativa var angustifolia) como grupo externo, por un lado, se encuentra el clado conformado por las especies Lathyrus 829, Lathyrus 830, L. odoratus, estas secuencias están relacionadas entre sí, correspondiendo al mismo taxón con un soporte de $96 \%$, y en el mismo grupo se encuentran las especies $L$. cassius Boiss., $L$. sativus, L. annuus L., y L. laevigatus (Waldst. \& Kit.) Gren., por otro lado, se distingue el clado que agrupa monofiléticamente a las especies, L. polyphyllus Nutt., L. holochlorus (Piper) C. Hitchc, L. vestitus Nutt., L. ledebourii Trautv., $L$. pannonicus (Jackq.) Gracke (Fig. 3A). A su vez, el árbol filogenético obtenido mediante el método de IB, muestra que Lathyrus 829, Lathyrus 830, y L. odoratus, corresponden al mismo taxón $(\mathrm{PP}=1,00)$, además emparentado con $L$. cassius (Fig. 3B). Las distancias genéticas entre pares de especies de Lathyrus revelado por el marcador ITS se pueden observar en la Tabla S2.

El árbol que muestra las relaciones filogenéticas de Lathyrus con las secuencias $p s b A-\operatorname{trn} H$, con el método NJ, muestra dos grupos monofiléticos y dos especies de Vicia (V. pisiformis y V. cracca) del grupo externo, por una parte, se encuentra un grupo monofilético el cual contiene un clado con politomía en su base, conformado por las muestras de Lathyrus 829, Lathyrus 830 y L. odoratus las que corresponderían a un mismo taxón esto con un soporte de $88 \%$, en este grupo monofilético también se encuentran las especies L. hirsutus, L. latifolius L., L. roseus Steven y L. rotundifolius Willd. Un segundo grupo monofilético está formado por L. davidii Hance y L. graminifolius (S. Watson) T. White (Fig. 4A).
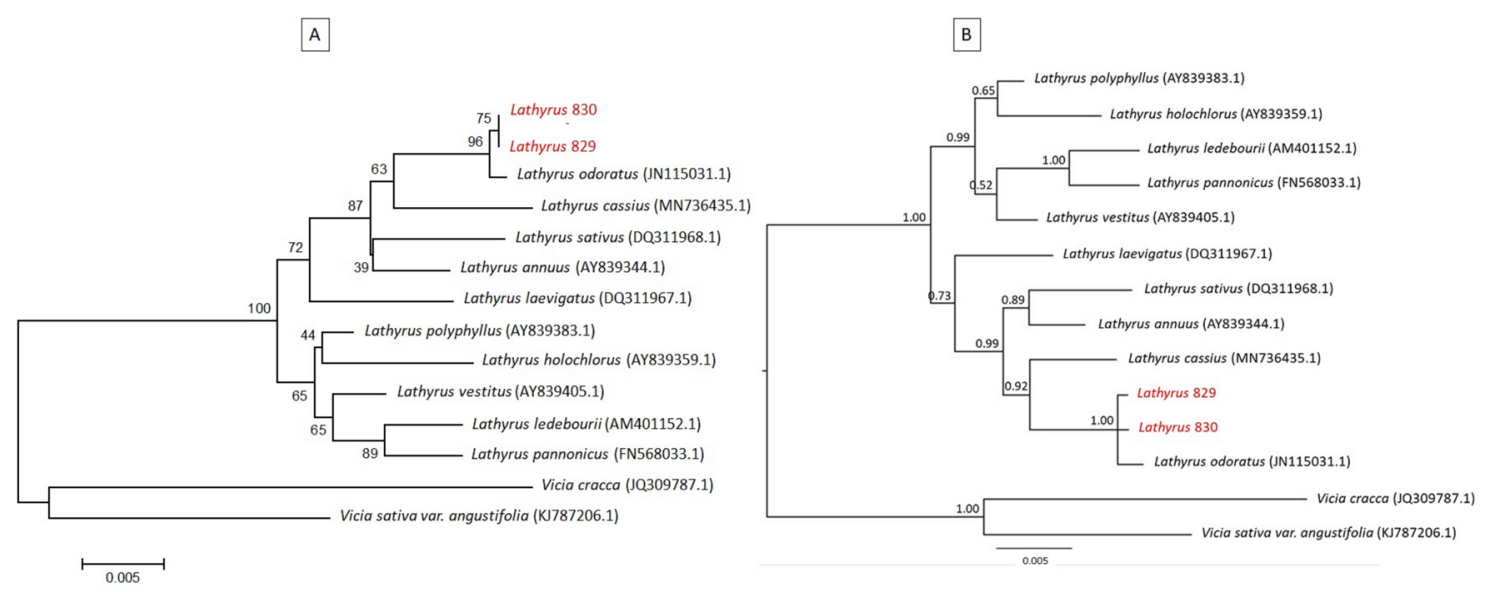

Fig. 3. Relaciones filogenéticas basadas en secuencias ITS de Lathyrus 829 y 830 y otras especies del género Lathyrus. A: Árbol filogenético realizado mediante método NJ, basado en el modelo modelo Tamura-Nei, los nodos presentan valores bootstrap. B: Árbol filogenético obtenido mediante IB (modelo de evolución $S Y M+G$ ), cuyos nodos indican valores PP. 


\section{Arias Aburto et al. - Análisis taxonómico molecular en Lathyrus}
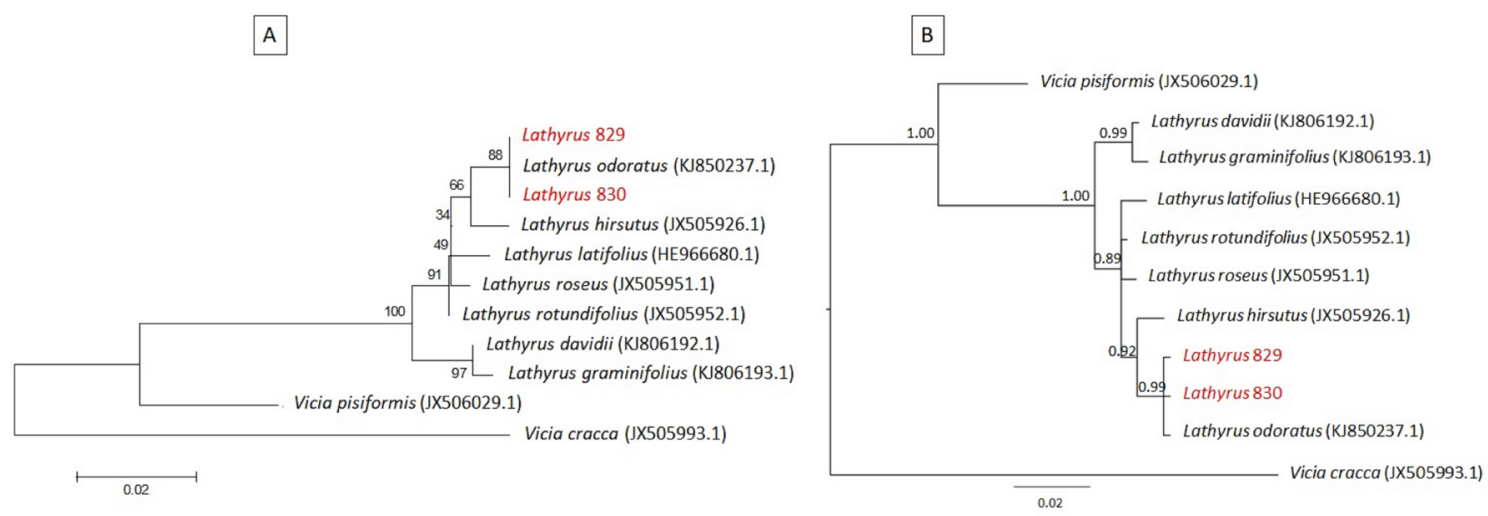

Fig. 4. Relaciones filogenéticas basadas en secuencias psbA-trnH de Lathyrus 829 y 830 y otras especies del género Lathyrus. A: Árbol filogenético realizado mediante método $\mathrm{NJ}$, basado en el modelo modelo Tamura-Nei, los nodos presentan valores bootstrap. B: Árbol filogenético obtenido mediante IB (modelo de evolución $\mathrm{GTR}+\mathrm{I})$, cuyos nodos indican valores PP.

El árbol generado con el método de IB, muestra que las secuencias de Lathyrus 829, Lathyrus 830 y L. odoratus son similares $(\mathrm{PP}=1,00)$ y están emparentadas a L. hirsutus (Fig. 4B). Las distancias genéticas entre pares de especies de Lathyrus revelado por el marcador $p s b A$-trnH se pueden observar en la Tabla S3.

El árbol con las secuencias matK en Lathyrus, dió como resultado dos grupos monofiléticos y dos especies de Vicia (V. nigricans Hook. \& Arn. y $V$. crocea (Desf.) Fritsch) del grupo externo, un clado constituido por Lathyrus 829, L. odoratus y Lathyrus 830, las cuales están relacionadas entre sí y se encuentran emparentadas a $L$. hirsutus con un soporte de $94 \%$, además en este grupo se encuentran las especies $L$. roseus, $L$. latifolius, L. sylvestris L., L. cicera y L. sativus. Un segundo clado que incluye L. tinginatus L. y L. inconspicuus L. (Fig. 5A). Por el método IB, el árbol filogenético generado agrupa en un clado
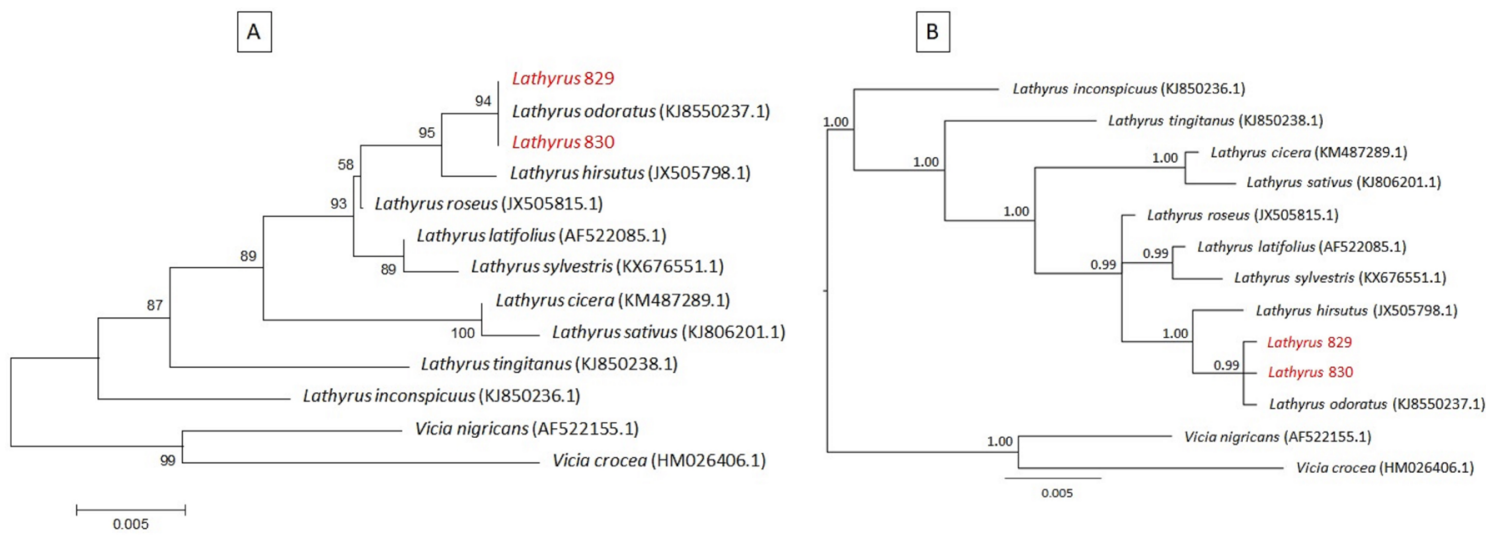

Fig. 5. Relaciones filogenéticas basadas en secuencias matK de Lathyrus 829 y 830 y otras especies del género Lathyrus. A: Árbol filogenético realizado mediante método NJ, basado en el modelo modelo Tamura-Nei, los nodos presentan valores bootstrap. B: Árbol filogenético obtenido mediante IB (modelo de evolución $G T R+G)$, cuyos nodos indican valores PP. 
a Lathyrus 829, Lathyrus 830 y L. odoratus, las cuales son secuencias idénticas $(\mathrm{PP}=1,00)$, además se encuentran emparentadas a L. hirsutus, con una probabilidad a posterior de 0,99 (Fig. 5B). Las distancias genéticas entre pares de especies de Lathyrus revelado por el marcador matK se pueden observar en la Tabla S4.

El árbol filogenético generado con las secuencias rpoC1 en Lathyrus con el método NJ, indica la formación de dos grupos monofiléticos, un primer gran grupo conformado por $L$. tinginatus, L. clymenum L., L. graminifolius, L. littoralis (Nutt.) Endl., L. japonicus, L. palustris L. y L. inconspicuus, además dos especies de Vicia ( $V$. sepium y $V$. ramuliflora). Un segundo grupo monofilético conformado por $L$. venosus Muhl. ex Willd., L. decaphyllus Pursh y L. davidii, además formando un clado las especies L. pubescens y L. sativus con Lathyrus 829, Lathyrus 830 y L. odoratus (Fig. 6A). Además, el árbol filogenético generado por el método IB indica que Lathyrus 829, Lathyrus 830 y L. odoratus se encuentran en una rama aparte $(\mathrm{PP}=1,00)$, formando un taxón (Fig. 6B). Las distancias genéticas entre pares de especies de Lathyrus revelado por el marcador rpoC1 se pueden observar en la Tabla S5.

El árbol filogenético de secuencias concatenadas (psbA-trnH, matK y rpoC1), mediante el método $\mathrm{NJ}$, presenta una separación basal de dos grupos monofiléticos y una especies de Vicia ( $V$. ramuliflora) del grupo externo, por un lado, se encuentra el clado conformado por las especies Lathyrus 829, Lathyrus 830, L. odoratus, relacionadas entre sí, como un mismo taxón con un soporte de $100 \%$, y en el mismo grupo se encuentran las especies L. sativus, $L$. pubescens y L. inconspicuus. Por otro lado, se distingue un clado que agrupa monofiléticamente a las especies, L. graminifolius, L. japonicus, L. davidii, L. venosus y L. ochroleucus Hook. (Fig. 7A). A su vez, el árbol filogenético obtenido mediante el método de IB, muestra que Lathyrus 829, Lathyrus 830, y L. odoratus, corresponden al mismo taxón $(\mathrm{PP}=1,00)$, emparentado con $L$. sativus (Fig. 7B).

En cuanto a caracterización morfológica, las muestras Lathyrus 829 y Lathyrus 830 mostraron racimos de 1 hasta 4 flores, cada flor de aproximadamente $4 \mathrm{~cm}$ de longitud, de color púrpura o azul y blanco-fucsia, hojas levemente pubescentes y peciolos alados. Dado estos rasgos, las características morfológicas de Lathyrus 829 y Lathyrus 830 se acercarían a la descripción de L. odoratus, de acuerdo a las claves descritas por Luchetti (2008).
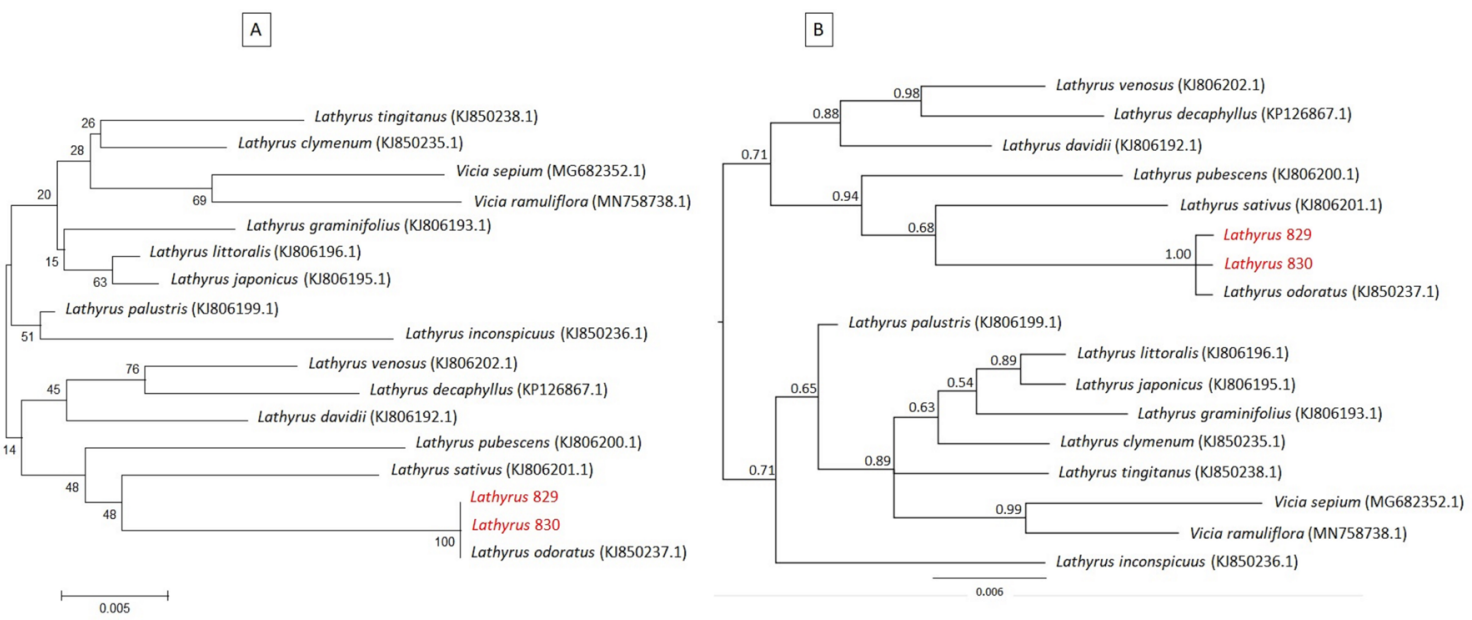

Fig. 6. Relaciones filogenéticas basadas en secuencias rpoC1 de Lathyrus 829 y 830 y otras especies del género Lathyrus. A: Árbol filogenético realizado mediante método NJ, basado en el modelo modelo Tamura-Nei, los nodos presentan valores bootstrap. B: Árbol filogenético obtenido mediante IB (modelo de evolución $G T R+I+G)$, cuyos nodos indican valores $P P$. 


\section{Arias Aburto et al. - Análisis taxonómico molecular en Lathyrus}
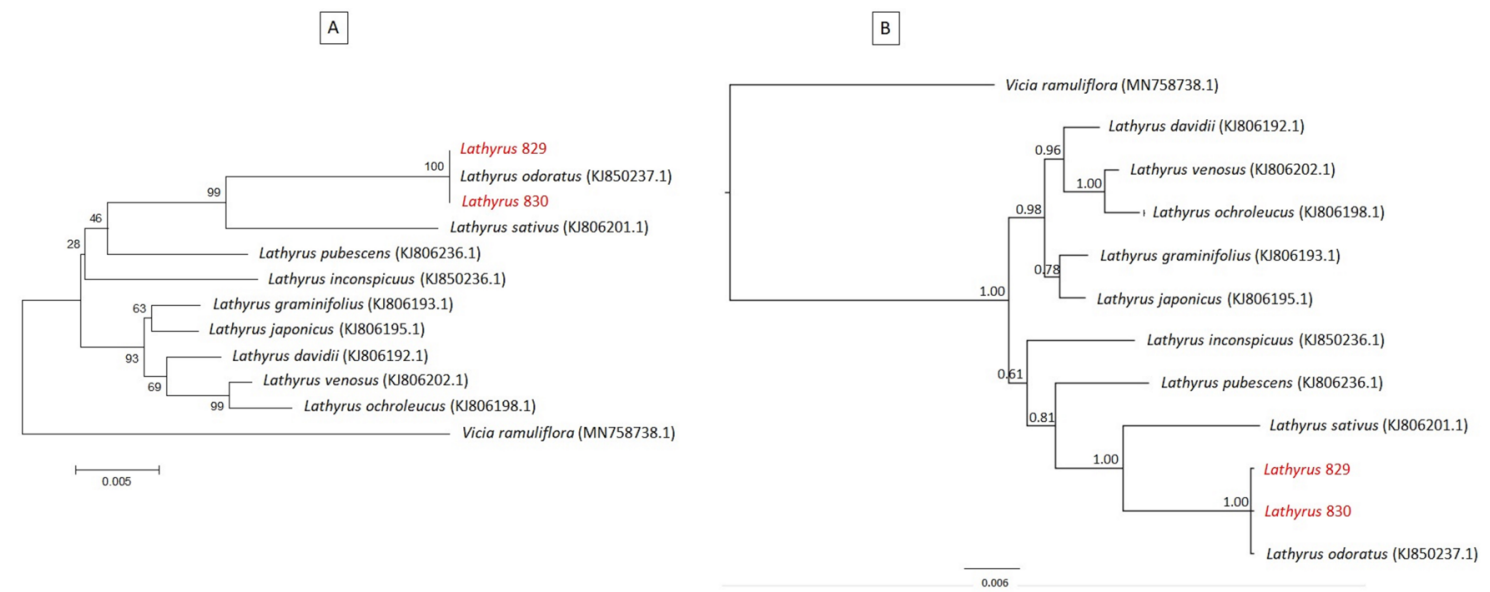

Fig. 7. Relaciones filogenéticas basadas en secuencias concatenadas ( $p s b A-t r n H$, matk y rpoC1) de Lathyrus 829 y 830 y otras especies del género Lathyrus. A: Árbol filogenético realizado mediante método $\mathrm{NJ}$, basado en el modelo modelo Tamura-Nei, los nodos presentan valores bootstrap. B: Árbol filogenético obtenido mediante IB (modelo de evolución GTR+I+G), cuyos nodos indican valores PP.

\section{Discusión}

Los cuatro loci de DNA barcoding, como la secuencia de ADN nuclear ITS y las secuencias de ADN cloroplastídico $p s b$-trnH, matK y rpoCl permitieron identificar genéticamente las muestras identificadas como Lathyrus 829 y Lathyrus 830, recolectadas en Arica, Chile. Los resultados indican que estas muestras están relacionadas a L. odoratus, lo cual se encuentra fuertemente apoyado por los arboles de consenso generados a partir de los análisis filogenéticos NJ e IB, como monofilética y separado de otras especies. Consecuentemente los métodos moleculares juegan un papel importante en la estimación de la relación entre individuos al comparar los genotipos con una serie de loci informativos (Sunnucks, 2000).

El primer árbol filogenético generado a partir de la secuencia ITS del presente trabajo, indica que el primer clado monofilético que incluye $L$. odoratus, L. cassius, L. sativus y L. annuus, con un soporte bootstrap de $87 \%$, corresponde a la sección Lathyrus. Los taxones L. odoratus, L. sativus y $L$. annuus se agrupan en la sección Lathyrus del árbol de consenso estricto de Asmussen \& Liston (1998) basados en secuencias rpoC e IR2. Adicionalmente, estas tres especies están agrupadas en la sección Lathyrus del árbol resultante del análisis combinado se secuencias ITS, trnL-F y $\operatorname{trn} S-G$ de acuerdo a Kenicer et al. (2005). La especie L. cassius se incluye en la sección Lathyrus a partir del árbol resultante del análisis de las secuencias matK según Oskoueiyan et al. (2014). Este primer clado también incluye a L. laevigatus, el cual corresponde a la sección Orobus (Kenicer et al., 2005). El segundo clado monofilético incluye especies de la sección Orobus y Lathyrostylis. Las especies L. polyphyllus, L. holochlorus, L. vestitus pertenecen a la sección Orobus (Kenicer et al., 2005). Por otro lado, las especies $L$. ledebourii y $L$. pannonicus, se incluyen en la sección Lathyrostylis (Kupicha, 1983). De acuerdo a lo señalado por Asmussen \& Liston (1998), es muy importante la comparación de filogenias de Lathyrus con ADN de genes nucleares (como por ejemplo ITS), debido a que pueden existir discrepancias entre los "árboles de genes" de cloroplasto.

En el segundo árbol filogenético generado a partir de las secuencias psbA-trnH, la especie $L$. odoratus se agrupa junto a L. hirsutus, L. latifolius, L. roseus y L. rotundifolius, que corresponden a la sección Lathyrus (Asmussen \& Liston, 1998; Kenicer et al., 2005; Oskoueiyan et al., 2014) y el segundo clado de este árbol, que involucra a $L$. davidii y L. graminifolius pertenece a la sección Orobus (Asmussen \& Liston, 1998). El tercer 
árbol generado a partir de las secuencias matK en Lathyrus spp., indica que L. odoratus pertenece a la sección Lathyrus, junto con L. hirsutus, $L$. roseus, L. latifolius, L. sylvestris, $L$. cicera y $L$. sativus (Asmussen \& Liston, 1998; Oskoueiyan et al.. 2014). Mientras que la especie L. tinginatus pertenece a la sección Lathyrus (Kupicha, 1983; Asmussen \& Liston, 1998; Kenicer et al., 2005; Oskoueiyan et al., 2014). Por otro lado la especie $L$. inconspicuus pertenece a la sección Linearicarpus (Kupicha 1983). El último árbol filogenético generado a partir de las secuencias rpoCl, agrupa dos clados monofiléticos. El primer clado no tiene una topología definida resuelta, ya que es posible encontrar especies de distintas secciones como de Orobus, Lathyrus, Clymenum, Linnearicarpus (Asmussen \& Liston, 1998; Kenicer et al., 2005; Oskoueiyan et al., 2014) incluyendo especies de Vicia del grupo externo ( $V$. sepium y V. ramuliflora). En el segundo clado es posible encontrar también especies de diferentes secciones como Notolathyrus y Lathyrus (Asmussen \& Liston, 1998). Sin duda, este marcador $r p o C l$ no es eficiente para discriminar secciones, incluso especies de Vicia se anidaron junto a especies de Lathyrus. Sin embargo, el estudio desarrollado por Asmussen \& Liston (1998) con secuencias rpoC discriminó eficientemente las secciones, esto porque además de utilizar la región rpoC1, estudió también datos del intrón, parte de rpoC2 y su espaciador intergénico, aportando más información al estudio.

En el árbol de secuencias concatenadas ( $p s b A$ trnH, matK y rpoC1), mostró un clado con especies de la sección Lathyrus, entre ellas Lathyrus 829 y $830, L$. odoratus y L. sativus, y especies de otras secciones como L. pubescens de la sección Notolathyrus y L. inconspicuus perteneciente a Linearicarpus (Kupicha, 1983). Por lo tanto, no es recomendable realizar análisis filogenéticos con estas tres regiones de secuencias concatenadas. Es muy probable que la información de la región rpoCl haya disminuido la resolución de los análisis concatenados, ya que los análisis filogenéticos por separado de las secuencias $p s b A$-trnH y matK, demostraron discriminar eficientemente especies y secciones.

El principal centro de distribución de la especie de Lathyrus es en la región Mediterránea oriental, con pequeños centros en el Norte y Sur América (Burkart, 1942). Sobre el origen de las especies endémicas Sudamericanas de Lathyrus, Asmussen \& Liston (1998) sustentan la hipótesis de que éstas derivan de linajes norteamericanos, consistente con la teoría de Kupicha (1983), quien planteó la hipótesis de que Lathyrus se originó en latitudes altas del Viejo Mundo, en el Cretácico o Terciario temprano, de aquí las especies originales de Lathyrus con características de la sección Orobus migraron a Norteamérica a través de Groenlandia o de Asia a través de Alaska y luego a Sudamérica donde la sección Notolathyrus evolucionó. Esta ruta de dispersión de la sección Notolathyrus de Norte a Sudamérica sigue la teoría del elemento de flora holártica sobre el origen de especies andinas, así como la hipótesis boreotrópica biogeográfica (Cleef, 1979; Simpson \& Todzia, 1990; Lavin \& Luckow, 1993)

En este estudio, la utilidad de las secuencias de nucleótidos de ITS, psbA-trnH y matK son efectivas como código de barras de ADN para la identificación de especies Lathyrus. La especie $L$. odoratus se encuentra naturalizada y creciendo de manera abundante en la Quebrada de Vitor, en una ubicación inhóspita, al oeste de Codpa y este del Valle de Chaca. Sin embargo, de acuerdo al Catálogo de las Plantas Vasculares de Chile de Rodriguez et al. (2018), L. odoratus no se ha registrado creciendo de manera natural en Chile. En Sudamérica se ha registrado L. odoratus creciendo naturalmente en Perú de acuerdo al ILDIS (International Legume Database and Information Service) (Roskov et al., 2020) y como cultivo en el sur de Córdoba (Argentina) (Bianco \& Kraus, 1996). No obstante, esta especie es cultivada en Chile con fines ornamentales, importándose su material bajo estrictas normas fitosanitarias (SAG, 2020). Esta especie es endémica del centro y sur de Europa, sin embargo, como especie ornamental está distribuida y cultivada en todo el mundo (Bianco \& Kraus, 1996). Por lo tanto, es posible que por ser una especie ornamental de amplio rango de cultivo, probablemente algún material de propagación de esta especie (en parcelas y jardines de agricultores ubicados a 2.000 m.s.n.m.) se diseminó producto de aluviones (producidos continuamente en la región cada año) y colonizó parte de la Quebrada de Vitor. Sin embargo, también es probable que esta especie haya sido introducida en la Quebrada de Vitor por colonos españoles.

Cabe mencionar que la Quebrada de Vitor, 


\section{Arias Aburto et al. - Análisis taxonómico molecular en Lathyrus}

es un área de interés para la conservación de la biodiversidad, allí se desarrollan especies nativas y además se han colectado varias especies vegetales de interés de conservación por su singularidad y escasa distribución en Chile, como es el caso de Haplorhus peruviana Engl. (especie rara) y Solanum peruvianum L, sin embargo, la actividad humana es evidente tanto por las parcelas, los cultivos y la introducción de numerosas malezas y especies forestales (Estades et al., 2009). El hallazgo reciente de L. odoratus en la Quebrada de Vitor, podría ser un riesgo para la conservación de la biodiversidad. Considerando que L. odoratus es una especie de fácil propagación, la cual podría constituirse como maleza que afecte a las especies nativas del lugar. El consumo de esta planta podría afectar a la fauna endémica, roedores exclusivos de la zona (Acevedo \& Olivares, 2012), ya que podría causar latirismo u osteolatirismo con consecuente deformidades esqueléticas, producto de la presencia de aminonitrilos neurotóxicos (McKay et al., 1954; Stamler, 1955). Según Kumar \& Duggal (2017), L. odoratus es una maleza nociva que afecta a los cultivos, cuyo hábito de enroscarse le permite una supervivencia mejor que otras malezas, lo cual le permite consumir grandes cantidades de recursos del hábitat y a su vez compite con especies nativas o cultivos. Sin duda este aspecto es importante de considerar si se piensa en mantener las condiciones actuales de esta zona geográfica. Considerando que para el Desierto de Atacama ya se han registrado 19 especies florales exóticas, como invasivas o con potencial invasivo, las cuales están afectando la biota nativa, estableciéndose en ecosistemas no intervenidos por el hombre, como orillas de esteros o en los sistemas costeros (Salinas, 2016). A todas luces esta especie podría tratarse de una especie introducida e invasora, que puede desequilibrar el ecosistema afectando la flora y fauna de la zona. Sin lugar a dudas, la conservación y protección de áreas de carácter único, que representan diversidad ecológica natural, asegura la continuidad de los procesos evolutivos, los patrones de flujo genético y la regulación del medio ambiente.

La presente investigación mediante relaciones filogenéticas con cuatro marcadores de código de barras de ADN (matK, ITS, psbA-trnH y rpoCl) evidenció el primer registro de individuos afines a $L$. odoratus creciendo de manera natural en Chile. Las secuencias ITS, psbA-trnH y matK demostraron ser eficientes en discriminar especies y secciones, sin embargo, la región rpoC1 no se recomienda su uso para diferenciar secciones de Lathyrus.

\section{Contribución de los Autores}

$\mathrm{RC}$ diseñó la investigación, coleccionó el material de campo y registró las muestras en herbario. MA y DR procesaron las muestras y realizaron los ensayos moleculares. MA y RC participaron en los análisis de datos y la escritura del manuscrito.

\section{Agradecimientos}

Los autores agradecen los valiosos comentarios entregados por los árbitros anónimos. Esta investigación fue financiada por el Fondo Regional de Innovación para la Competitividad Regional (FIC Regional, 2018) del Gobierno Regional de Atacama, Código BIP 40013338-0. Agradecemos el apoyo entregado por los profesionales de la Secretaría Regional Ministerial de Medio Ambiente de la Región de Arica-Parinacota y datos de especies facilitados por la académica Eliana Belmonte Schwarzbaum de la Universidad de Tarapacá.

\section{Bibliografía}

ACEVEDO, C. \& F. OLIVARES. 2012. Guía Descriptiva "Flora y Fauna de la Región de Atacama". Tierra del Sol Consultores \& CAP Minería, Minera Hierro Atacama. Vallenar, Chile.

ASMUSSEN, C. B. \& A. LISTON. 1998. Chloroplast DNA characters, phylogeny, and classification of Lathyrus (Fabaceae). Am. J. Bot. 85: 387-401. http://doi.org/10.2307/2446332

BARCACCIA, G., M. LUCCHIN \& M. CASSANDRO. 2016. DNA Barcoding as a molecular tool to track down mislabeling and food piracy. Diversity 8: 1424-2818. http://doi.org/10.3390/d8010002

BIANCO, C. A. \& T. A. KRAUS. 1996. Las especies de Lathyrus (Leguminosae) silvestres y cultivadas del sur de la Provincia de Córdoba, República Argentina. Rev. Fac. Agronomía - UNLPam 9: 33-48. 
BIOSOFT, H. 2012. DNA Baser Sequence Assembler, v4.10. Heracle BioSoft SRL., Romania. http://www. dnabaser.com/download/download.html [Acceso: 29 Agosto 2020]

BURKART, A. 1935. Revisión de las especies de Lathyrus de la República Argentina. Revista Fac. Agron. Veterin. 8: 41-128.

BURKART, A. 1942. Nuevas contribuciones a la sistemática de las especies sudamericanas de Lathyrus. Darwiniana 6: 9-30. http://doi.org/10.2307 / 23211565

CALVO, J. \& A. MOREIRA-MUÑOZ. 2018. Nuevas adiciones a la flora introducida de Chile. Darwiniana 6: 179-185.

http://doi.org/10.14522/darwiniana.2018.62.801

CBOL PLANT WORKING GROUP. 2009. A DNA barcode for land plants. P. Natl. Acad. Sci. USA 106:12794-12797. http://doi.org/10.1073/pnas.0905845106

CHALUP, L. \& J. G. SEIJO. 2007. Caracterización de las especies sudamericanas de Lathyrus por FISH. XXVIII Jornadas Argentinas de Botanica. Disponible en: https://www.conicet.gov.ar/new_scp/detalle.php ?keywords $=\& \mathrm{id}=05434 \&$ inst $=$ yes $\&$ congresos $=$ yes \&detalles=yes\&congr_id=387906 [Acceso: 28 Julio 2020]

CLEEF, A. M. 1979. The phytogeographical position of the neotropical vascular piramo flora with special reference to the Colombian Cordillera Oriental. In: K. LARSEN \& L. B. HOLM-NIELSEN eds. Tropical Botany. Academic Press, London.

CONTRERAS, R., V. PORCILE, D. GUGGIANA-NILO \& F. AGUAYO. 2019. An efficient protocol to perform genetic traceability of tissue and foods from Geoffroea decorticans. Chilean J. Agric. Anim. Sci. 35: 224-237. http://doi.org/10.4067/S0719-38902019005000402

CONTRERAS, R., L VAN DEN BRINK, B. BURGOS, M. GONZÁLEZ, S. GACITÚA. 2020a. Genetic characterization of an endangered Chilean endemic species, Prosopis burkartii Muñoz, reveals its hybrids parentage. Plants 9: 744. https://doi.org/10.3390/plants9060744

CONTRERAS, R., L. VAN DEN BRINK, B. SEPÚLVEDA, F. AGUAYO \& V. PORCILE. 2020 b. Phylogenetic relationships of plant species from the flowering desert of the Atacama Region. Blacpma 19: 300-313.

CZEFRANOVA, Z. V. 1971. Review of the species of the genus Lens Mill. Novosti Sist. Vyssh. Rast. 8: 184-191.
CUÉNOUD, P., V. SAVOLAINEN, L. W. CHATROU, M. POWELL, R. J. GRAYER \& M. W. CHASE. 2002. Molecular phylogenetics of caryophyllales based on nuclear 18S rDNA and plastid $r b c L$, atpB, and matK DNA sequences. Am. J. Bot. 89: 132-144. http://doi.org/ 10.3732/ajb.89.1.132

DONG, W., C. XU, T. CHENG, K. LIN \& S. ZHOU. 2013. Sequencing angiosperm plastid genomes made easy: A complete set of universal primers and a case study on the phylogeny of Saxifragales. Genome Biol. Evol. 5: 989-997. http://doi.org/10.1093/gbe/evt063

ESTADES, C. F., M. L. ANDRADE, V. LATORRE, M. A. VUKASOVIC \& M. T. SERRA. 2009. Elaboración de línea base, zonificación y guía de manejo de un predio fiscal, sitio prioritario para la conservación de la biodiversidad en la Quebrada de Chaca, Región de Arica y Parinacota. Comisión Nacional del Medio Ambiente (CONAMA), Santiago, Chile.

FAÚNDEZ, L., R. FLORES, A. FAÚNDEZ \& M. TREUMÚN. 2014. Reino Plantae. In: J. HERNÁNDEZ, C. ESTADES, L. FAÚNDEZ \& J. HERREROS DE LARTUNDO (eds.), Biodiversidad Terrestre de la Región de Arica y Parinacota, pp. 164229. Ministerio del Medio Ambiente (MMA), Facultad de Ciencias Forestales y de la Conservación de la Naturaleza, Universidad de Chile, Santiago, Chile.

GATICA-CASTRO, A., A. MARTICORENA, G. ROJAS, G. ARANCIO \& F. A. SQUEO. 2015. Estado de conservación de la flora nativa de las regiones de Arica-Parinacota y de Tarapacá, Chile. Gayana Bot. 72: 305-339. http://doi.org/10.4067/S0717-66432015000200013

HARTLEY, A. J., G. CHONG, J. HOUSTON \& A. MATHER. 2005. 150 million years of climatic stability: evidence from the Atacama Desert, Northern Chile. $J$. Geol. Soc. London 162: 421-24. http://doi.org/10.1144/0016-764904-071

HEIBL, C. \& S. RENNER. 2012. Distribution models and a dated phylogeny for Chilean Oxalis species reveal occupation of new habitats by different lineages, not rapid adaptive radiation. Syst. Biol. 61:823-834. http://doi.org/10.1093/sysbio/sys034

HILLIS, D. \& J. BULL. 1993. An empirical test of bootstrapping as a method for assessing confidence in phylogenetic analysis. Syst. Biol. 42: 182-192. http://doi.org/10.1093/sysbio/42.2.182

HOLLINGSWORTH, P. 2011. Refining the DNA barcode for land plants. PNAS USA 108: 19451-19452. http://doi.org/10.1073/pnas.1116812108 


\section{Arias Aburto et al. - Análisis taxonómico molecular en Lathyrus}

KENICER, G. J., T. KAJITA, R. T. PENNINGTON \& J. MURATA. 2005. Systematics and biogeography of Lathyrus (Leguminosae) based on internal transcribed spacer and cpDNA sequence data. Am. J. Bot. 92: 1199-1209.

http://doi.org/10.3732/ajb.92.7.1199

KENICER, G. 2008. An introduction to the genus Lathyrus L. Curtis's bot. mag. 25: 286-295. http://doi.org/10.1111/j.1467-8748.2008.00632.x

KRESS, W. J., K. J. WURDACK, E. A. ZIMMER, L. A. WEIGT \& D. H. JANZEN. 2005. Use of DNA barcodes to identify flowering plants. PNAS USA 102: 8369-8374. http://doi.org/10.1073/pnas.0503123102

KUMAR, S. \& S. DUGGAL. 2017. A Survey of weeds of wheat crop fields in Narwana region, India. Int. J. Sci. Res. 5: 6664-6669. http://doi.org/10.18535/ijsrm/v5i8.13

KUPICHA, F. K. 1983. The infrageneric structure of Lathyrus. Notes Roy. Bot. Gard. Edinburgh 41: 209-244.

LAHAYE, R., M. BANK, D. BOGARIN, J. WARNER, F. PUPULIN, G. GIGOT, O. MAURIN, S. DUTHOIT, T.G BARRACLOUGH \& V. SAVOLAINEN. 2008. DNA barcoding the floras of biodiversity hotspots. PNAS USA 105: 2923-292.

http://doi.org/10.1073/pnas.0709936105

LAVIN, M., J. J. DOYLE \& J. D. PALMER. 1990. Evolutionary significance of the loss of the chloroplast-DNA inverted repeat in the Leguminosae subfamily Papilionoideae. Evolution 44: 390-402. http://doi.org/10.2307/2409416

LUEBERT, F. \& R. GAJARDO. 2005. Vegetación alto-andina de Parinacota (norte de Chile) y una sinopsis de la vegetación de la Puna meridional. Phytocoenologia 35: 79-128. http://doi.org/10.1127/0340-269X/2005/0035-0079

LUCHETTI, A. M. 2008. Claves para el Reconocimiento de las especies santafesinas de Leguminosas Papilionoideas. Nat. Neotrop. 1: 47-81. http://doi.org/10.14409/natura.v1i39.3868

MCKAY, G. F., J. J. LALICH, E. D. SCHILLING \& F. M. STRONG. 1954. A crystalline "Lathyrus factor" from Lathyrus odoratus. Arch Biochem Biophys 52: 313-322. http://doi.org/10.1016 / 0003-9861 (54) 90129-0

NARAVAN, R. K. J. \& A. DURRANT. 1983. DNA distribution in chromosomes of Lathyrus species. Genetica 61: 47-53. http://doi.org/10.1007/BF00563231
NYLANDER, J. A. A. 2008. MrModeltest 2.3. Department of Systematic Zoology, Uppsala University, Uppsala, Suecia. Disponible en: https://github.com/nylander/ MrModeltest2 [Acceso: 29 Agosto 2020]

OSKOUEIYAN, R., S. KAZEMPOUR \& A. AMIRAHMADI. 2014. Molecular Phylogeny of the Genus Lathyrus (Fabaceae-Fabeae) Based on cpDNA matK Sequence in Iran. Iran J. Biotechnol. 12: 41-48. http://doi.org/10.5812/ijb.10315

PNUD (Programa de las Naciones Unidas para el Desarrollo). 2017. Catálogo de las especies exóticas asilvestradas/naturalizadas en Chile. Laboratorio de Invasiones Biológicas (LIB) Universidad de Concepción, Proyecto GEF/MMA/PNUD. Fortalecimiento de los Marcos Nacionales para la Gobernabilidad de las Especies Exóticas Invasoras: Proyecto Piloto en el Archipiélago de Juan Fernández. Santiago, Chile.

RAMBAUT, A. \& A. J. DRUMMOND. 2007. Tracer 1.5.0. University of Edinburgh, Edimburgo, Escocia. Disponible en: http://beast.bio.ed.ac.uk/Tracer.

RAMBAUT, A. 2012. FigTree (version 1.4.0). Disponible en: http://tree.bio.ed.ac.uk/software/figtree [Acceso: 28 Julio 2020]

RODRIGUEZ, R., C.MARTICORENA, D.ALARCÓN,C. BAEZA, L. CAVIERES, V. L. FINOT, N. FUENTES, A. KIESSLING, M. MIHOC, A. PAUCHARD, E. RUIZ, P. SANCHEZ \& A. MARTICORENA. 2018. Catálogo de las plantas vasculares de Chile. Gayana Bot. 75: 1-430. http://doi.org/10.4067/S0717-66432018000100001

RONQUIST, F., M. TESLENKO, P. VAN DER MARK, D. L. AYRES, A. DARLING, S. HÖHNA, B. LARGET, L. LIU, M. A. SUCHARD \& J. P. HUELSENBECK. 2012. MrBayes 3.2: efficient Bayesian phylogenetic inference and model choice across a large model space. Syst. Biol. 61: 539-542.

http://doi.org/10.1093/sysbio/sys029

ROSKOV, Y., J. ZARUCCHI, M. NOVOSELOVA \& F. BISBY (eds). 2020. ILDIS World Database of Legumes (version 12, May 2014). In: ROSKOV, Y., G. OWER, T. ORRELL, D. NICOLSON, N. BAILLY, P. M. KIRK, T. BOURGOIN, R. E. DEWALT, W. DECOCK, E. VAN NIEUKERKEN, J. ZARUCCHI \& L. PENEV, EDS. Species 2000 \& ITIS Catalogue of Life, 2019 Annual Checklist. Recurso digital en www. catalogueoflife.org/annual-checklist/2019. Species 2000: Naturalis, Leiden, Holanda.

SAG (Servicio Agrícola y Ganadero). 2020. Ministerio de Agricultura, Santiago, Chile. Disponible en: 
https://www.sag.gob.cl/sites/default/files/ resolucion_2020_2009.pdf [Acceso: 26 agosto 2020]

SALINAS, P. R. 2016. Diagnóstico, estado y tendencias de la biodiversidad: Región de Atacama. Ministerio de medio ambiente, Santiago, Chile.

SENN, H.A. 1938. Experimental data for a revision of the genus Lathyrus. Am. J. B. 25: 67-78. http://doi.org/10.1002/j.1537-2197.1938.tb09188.x

SIMOLA, L. K. 1968. A serological comparison of the seed proteins of the genus Lathyrus and certain other genera of the Papilionaceae. Flora 158: 645-658. https://doi.org/10.1016/S0367-1801(17)30248-X

SIMPSON, B. B. \& C. A. TODZIA. 1990. Patterns and processes in the development of the high Andean flora. Am. J. Bot. 77: 1419-1432. http://doi.org/10.2307/2444752

SKIBA, B., A. M. GURUNG \& E. C. K. PANG. 2007. Genome Mapping and Molecular Breeding in Lathyrus. In: KOLE C. (eds) Pulses, Sugar and Tuber Crops. Genome Mapping and Molecular Breeding in Plants, vol 3. Springer, Berlin, Alemania.

STAMLER, F. W. 1955. Reproduction in Rats Fed Lathyrus Peas or Aminonitriles. Proc. Soc. Exp. Biol. Med. 90: 294-298.

http://doi.org/10.3181/00379727-90-22013
STANFORD, A. M, R. HARDEN \& C. R. PARKS. 2000. Phylogeny and biogeography of Juglans (Juglandaceae) based on $m a t K$ and ITS sequence data. Am. J. Bot. 87: 872-882. http://doi.org/10.2307/2656895

SUNNUCKS, P. 2000. Efficient genetic markers for population biology. Trends Ecol. Evol. 15: 199203.

http://doi.org/ 10.1016/S0169-5347(00)01825-5

TAMURA, K., \& M. NEI. 1993. Estimation of the number of nucleotide substitutions in the control region of mitochondrial DNA in humans and chimpanzees. Mol. Biol. Evol. 10: 512-526.

http://doi.org/10.1093/oxfordjournals.molbev. a040023

TAMURA, K., G. STECHER, D. PETERSON, A. FILIPSKI \& S. KUMAR. 2013. MEGA6: Molecular Evolutionary Genetics Analysis version 6.0. Mol. Biol. Evol. 30: 2725-2729. http://doi.org/10.1093/molbev/mst197

YAMAMOTO, K., T. FUJIWARA \& I. D. BLUMENREICH, 1984. Karyotypes and morphological characteristics of some species in the genus Lathyrus L. Jpn. J. Breed. 34: 273-284. http://doi.org/10.1270/jsbbs1951.34.273 


\section{Arias Aburto et al. - Análisis taxonómico molecular en Lathyrus}

Material Suplementario

Tabla S1. Sección, nombre cientifico y accesión de especies de Lathyrus

\begin{tabular}{|c|c|c|}
\hline Sección & Nombre científico & Accesión \\
\hline Lathyrus & L. cassius Boiss & MN736435 \\
\hline Lathyrus & L. sativus $L$. & DQ311968, KJ806201 \\
\hline Lathyrus & L. annuus L. & AY839344 \\
\hline Lathyrus & L. odoratus L. & JN115031, KJ850237 \\
\hline Lathyrus & L. hirsutus L. & JX505926 \\
\hline Lathyrus & L. latifolius $\mathrm{L}$ & HE966680 \\
\hline Lathyrus & L. roseus Steven & JX505951 \\
\hline Lathyrus & L. rotundifolius Willd & JX505952 \\
\hline Lathyrus & L. sylvestris L. & KX676551 \\
\hline Lathyrus & L. cicera L. & KM487289 \\
\hline Lathyrus & L. tinginatus $\mathrm{L}$. & KJ850238 \\
\hline Orobus & L. laevigatus (Waldst. \& Kit.) Gren. & DQ311967 \\
\hline Orobus & L. polyphyllus Nutt. & AY839383 \\
\hline Orobus & L. holochlorus (Piper) C. Hitchc & AY839359 \\
\hline Orobus & L. vestitus Nutt. & AY839405 \\
\hline Orobus & L. davidii Hance & KJ806192 \\
\hline Orobus & L. graminifolius (S. Watson) T. White & KJ806193 \\
\hline Orobus & L. littoralis (Nutt.) Endl. & KJ806196 \\
\hline Orobus & L. palustris L. & KJ806199 \\
\hline Orobus & L. venosus Muhl. ex Willd. & KJ806202 \\
\hline Orobus & L. japonicus Willd. & KJ806195 \\
\hline Lathyrostylis & L. ledebourii Trautv. & AY839405, AM401152 \\
\hline Lathyrostylis & L. pannonicus (Jackq.) Gracke & FN568033 \\
\hline Linearicarpus & L. inconspicuus L. & KJ850236 \\
\hline Clymenum & L. clymenum L. & KJ850235 \\
\hline ------- & L. decaphyllus Pursh & KP126867 \\
\hline Notolathyrus & L. pubescens Hook. \& Arn & KJ806200 \\
\hline ------- & L. ochroleucus Hook. & KJ806198 \\
\hline
\end{tabular}


Bol. Soc. Argent. Bot. 55 (3) 2020

Tabla S2. Distancia genética entre pares de especies de Lathyrus y de Vicia del grupo externo revelada por el marcador ITS

\begin{tabular}{|c|c|c|c|c|c|c|c|c|c|c|c|c|c|c|}
\hline Taxon & 1 & 2 & 3 & 4 & 5 & 6 & 7 & 8 & 9 & 10 & 11 & 12 & 13 & 14 \\
\hline \multicolumn{15}{|l|}{ Lathyrus_829 } \\
\hline Lathyrus_830 & 0,000 & & & & & & & & & & & & & \\
\hline $\begin{array}{l}\text { JN115031.1_- } \\
\text { Lathyrus_odoratus }\end{array}$ & 0,002 & 0,002 & & & & & & & & & & & & \\
\hline $\begin{array}{l}\text { AY839383.1_- } \\
\text { Lathyrus_polyphyllus }\end{array}$ & 0,019 & 0,019 & 0,017 & & & & & & & & & & & \\
\hline $\begin{array}{l}\text { DQ311968.1_- } \\
\text { Lathyrus_sativus }\end{array}$ & 0,016 & 0,016 & 0,018 & 0,019 & & & & & & & & & & \\
\hline $\begin{array}{l}\text { AM401152.1_- } \\
\text { Lathyrus_ledebourii }\end{array}$ & 0,024 & 0,024 & 0,026 & 0,011 & 0,024 & & & & & & & & & \\
\hline $\begin{array}{l}\text { DQ311967.1_- } \\
\text { Lathyrus_laevigatus }\end{array}$ & 0,021 & 0,021 & 0,019 & 0,014 & 0,021 & 0,023 & & & & & & & & \\
\hline $\begin{array}{l}\text { AY839359.1_Lathyrus_ } \\
\text { holochlorus }\end{array}$ & 0,028 & 0,028 & 0,026 & 0,011 & 0,028 & 0,019 & 0,023 & & & & & & & \\
\hline $\begin{array}{l}\text { AY839405.1_- } \\
\text { Lathyrus_vestitus }\end{array}$ & 0,019 & 0,019 & 0,021 & 0,006 & 0,019 & 0,011 & 0,018 & 0,014 & & & & & & \\
\hline $\begin{array}{l}\text { FN568033.1_- } \\
\text { Lathyrus_pannonicus }\end{array}$ & 0,024 & 0,024 & 0,026 & 0,011 & 0,024 & 0,009 & 0,023 & 0,019 & 0,011 & & & & & \\
\hline $\begin{array}{l}\text { MN736435.1_- } \\
\text { Lathyrus_cassius }\end{array}$ & 0,014 & 0,014 & 0,016 & 0,021 & 0,018 & 0,026 & 0,022 & 0,029 & 0,021 & 0,026 & & & & \\
\hline $\begin{array}{l}\text { AY839344.1_ } \\
\text { Lathyrus_annuus }\end{array}$ & 0,013 & 0,013 & 0,014 & 0,016 & 0,013 & 0,021 & 0,018 & 0,024 & 0,016 & 0,021 & 0,014 & & & \\
\hline $\begin{array}{l}\text { JQ309787.1_- } \\
\text { Vicia_cracca }\end{array}$ & 0,059 & 0,059 & 0,057 & 0,052 & 0,059 & 0,061 & 0,057 & 0,058 & 0,056 & 0,061 & 0,063 & 0,058 & & \\
\hline $\begin{array}{l}\text { KJ787206.1_Vicia_ } \\
\text { sativa_var._angustifolia }\end{array}$ & 0,049 & 0,049 & 0,051 & 0,042 & 0,049 & 0,043 & 0,047 & 0,045 & 0,041 & 0,043 & 0,051 & 0,044 & 0,047 & \\
\hline
\end{tabular}

Tabla S3. Distancia genética entre pares de especies de Lathyrus y de Vicia del grupo externo revelada por el marcador psbA-trnH

\begin{tabular}{|c|c|c|c|c|c|c|c|c|c|c|c|}
\hline Taxon & 1 & 2 & 3 & 4 & 5 & 6 & 7 & 8 & 9 & 10 & 11 \\
\hline \multicolumn{12}{|l|}{ Lathyrus_829 } \\
\hline Lathyrus_830 & 0,000 & & & & & & & & & & \\
\hline KJ850237.1_Lathyrus_odoratus & 0,000 & 0,000 & & & & & & & & & \\
\hline KJ806192.1_Lathyrus_davidii & 0,026 & 0,026 & 0,026 & & & & & & & & \\
\hline KJ806193.1_Lathyrus_graminifolius & 0,030 & 0,030 & 0,030 & 0,003 & & & & & & & \\
\hline HE966680.1_Lathyrus_latifolius & 0,016 & 0,016 & 0,016 & 0,023 & 0,026 & & & & & & \\
\hline JX505952.1_Lathyrus_rotundifolius & 0,010 & 0,010 & 0,010 & 0,016 & 0,019 & 0,006 & & & & & \\
\hline JX505951.1_Lathyrus_roseus & 0,013 & 0,013 & 0,013 & 0,019 & 0,023 & 0,010 & 0,003 & & & & \\
\hline JX505926.1_Lathyrus_hirsutus & 0,013 & 0,013 & 0,013 & 0,026 & 0,030 & 0,016 & 0,010 & 0,013 & & & \\
\hline JX505993.1_Vicia_cracca & 0,164 & 0,164 & 0,164 & 0,159 & 0,164 & 0,164 & 0,154 & 0,159 & 0,164 & & \\
\hline JX506029.1_Vicia_pisiformis & 0,085 & 0,085 & 0,085 & 0,077 & 0,081 & 0,081 & 0,074 & 0,077 & 0,086 & 0,126 & \\
\hline
\end{tabular}




\section{Arias Aburto et al. - Análisis taxonómico molecular en Lathyrus}

Tabla S4. Distancia genética entre pares de especies de Lathyrus y de Vicia del grupo externo revelada por el marcador matK

\begin{tabular}{|c|c|c|c|c|c|c|c|c|c|c|c|c|c|}
\hline Taxon & 1 & 2 & 3 & 4 & 5 & 6 & 7 & 8 & 9 & 10 & 11 & 12 & 13 \\
\hline \multicolumn{14}{|l|}{ Lathyrus_829 } \\
\hline Lathyrus_830 & 0,000 & & & & & & & & & & & & \\
\hline $\begin{array}{l}\text { KJ850237.1_ } \\
\text { Lathyrus_odoratus }\end{array}$ & 0,000 & 0,000 & & & & & & & & & & & \\
\hline $\begin{array}{l}\text { JX505815.1__ } \\
\text { Lathyrus_roseus }\end{array}$ & 0,006 & 0,006 & 0,006 & & & & & & & & & & \\
\hline $\begin{array}{l}\text { AF522085.1_- } \\
\text { Lathyrus_latifolius }\end{array}$ & 0,009 & 0,009 & 0,009 & 0,003 & & & & & & & & & \\
\hline $\begin{array}{l}\text { JX505798.1_- } \\
\text { Lathyrus_hirsutus }\end{array}$ & 0,005 & 0,005 & 0,005 & 0,006 & 0,009 & & & & & & & & \\
\hline $\begin{array}{l}\text { KM487289.1_ } \\
\text { Lathyrus_cicera }\end{array}$ & 0,021 & 0,021 & 0,021 & 0,014 & 0,017 & 0,021 & & & & & & & \\
\hline $\begin{array}{l}\text { KJ806201.1_- } \\
\text { Lathyrus_sativus }\end{array}$ & 0,024 & 0,024 & 0,024 & 0,017 & 0,020 & 0,024 & 0,003 & & & & & & \\
\hline $\begin{array}{l}\text { KJ850238.1_- } \\
\text { Lathyrus_tingitanus }\end{array}$ & 0,026 & 0,026 & 0,026 & 0,020 & 0,022 & 0,026 & 0,024 & 0,026 & & & & & \\
\hline $\begin{array}{l}\text { KJ850236.1_Lathyrus_ } \\
\text { inconspicuus }\end{array}$ & 0,026 & 0,026 & 0,026 & 0,022 & 0,022 & 0,026 & 0,029 & 0,032 & 0,024 & & & & \\
\hline $\begin{array}{l}\text { KX676551.1_- } \\
\text { Lathyrus_sylvestris }\end{array}$ & 0,012 & 0,012 & 0,012 & 0,005 & 0,003 & 0,012 & 0,018 & 0,021 & 0,025 & 0,025 & & & \\
\hline $\begin{array}{l}\text { AF522155.1_ } \\
\text { Vicia_nigricans }\end{array}$ & 0,042 & 0,042 & 0,042 & 0,037 & 0,037 & 0,039 & 0,038 & 0,040 & 0,036 & 0,030 & 0,037 & & \\
\hline $\begin{array}{l}\text { HM026406.1_- } \\
\text { Vicia_crocea }\end{array}$ & 0,046 & 0,046 & 0,046 & 0,042 & 0,042 & 0,043 & 0,049 & 0,052 & 0,042 & 0,037 & 0,045 & 0,026 & \\
\hline
\end{tabular}




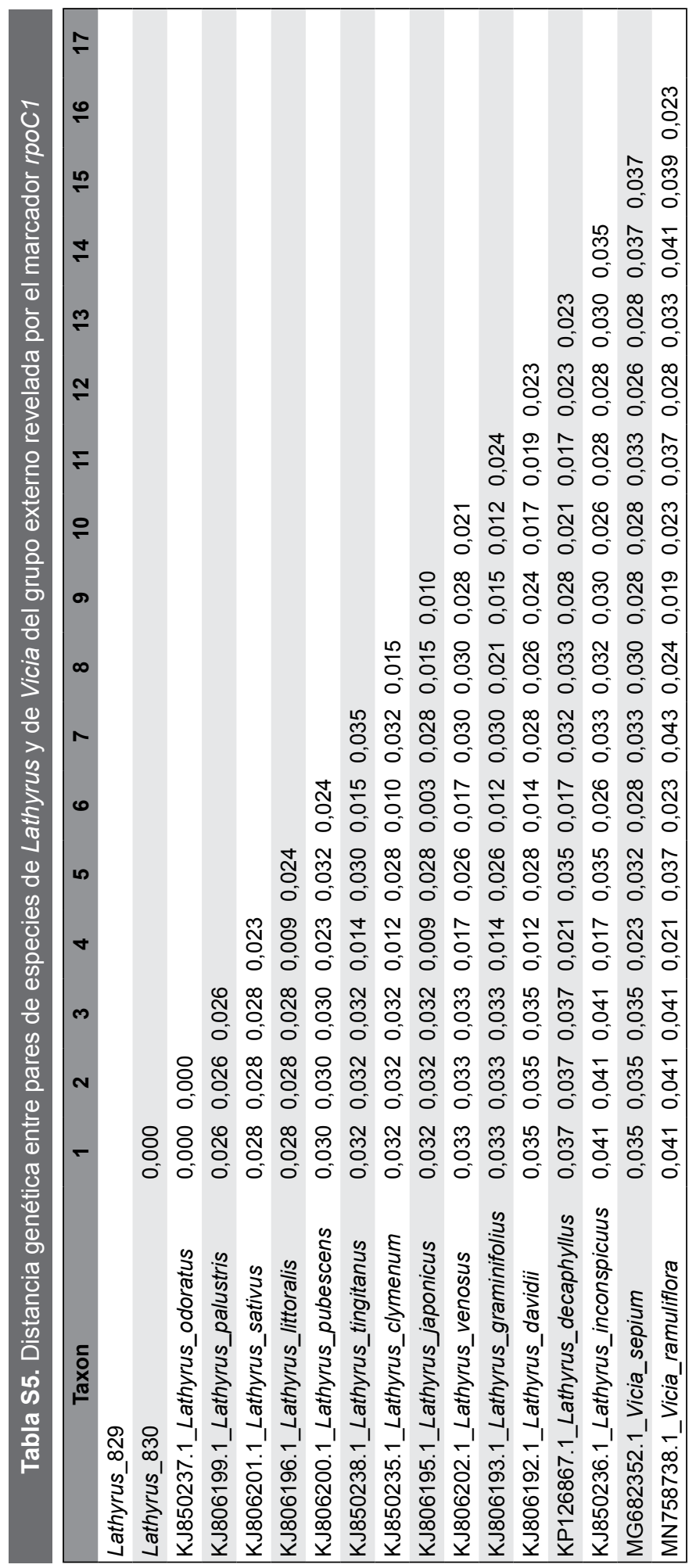

